\author{
Military Technical College \\ Kobry El-Kobbah, \\ Cairo, Egypt.
}

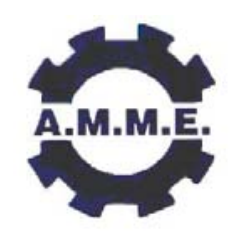

\title{
A COMPUTATIONAL FLUID DYNAMICS EVALUATION OF A PNEUMATIC SAFETY RELIEF VALVE
}

\author{
DEMPSTER* W. and ELMAYYAH**W.
}

\begin{abstract}
Safety relief valves are well established components preventing catastrophic failure of pressurised systems when non-normal operating conditions occur. However, it is only recently with developments in CFD techniques that the capability to predict the complex flow conditions occurring in the valves has been possible resulting in only limited studies being found in the literature. This paper presents experimental and theoretical investigations applied to a safety relief valve designed for the refrigeration industry but extended here to consider pneumatic systems since air is the compressible fluid. The discharge flow rate and valve forces are determined both theoretically and experimentally for different valve lift conditions and related to the detailed flow conditions (pressure, temperature and Mach number) in the valve predicted by CFD techniques. The CFD code FLUENT has been used with a two dimensional axisymmetric RANS approach using the $k-\varepsilon$ turbulent model to predict the highly compressible flow through the valve. The model has been validated by comparison with experimental measurements and the predicted results show good agreement, providing confidence in the use of CFD techniques for valve design and improvement.
\end{abstract}

\section{KEY WORDS}

Pneumatics, Safety relief valves, Computational fluid dynamics, Compressible flow.

* Lecturer, Dept. of Mechanical Engineering, University of Strathclyde, Glasgow, UK. Email: william.dempster@strath.ac.uk, Tel.: +441415482044, Fax: +441415525105

** PhD research student, Dept. of Mechanical Engineering, University of Strathclyde, Glasgow, UK. Email: wael.elmayyah@strath.ac.uk, Tel.: +447515377732 


\section{NOMENCLATURE}

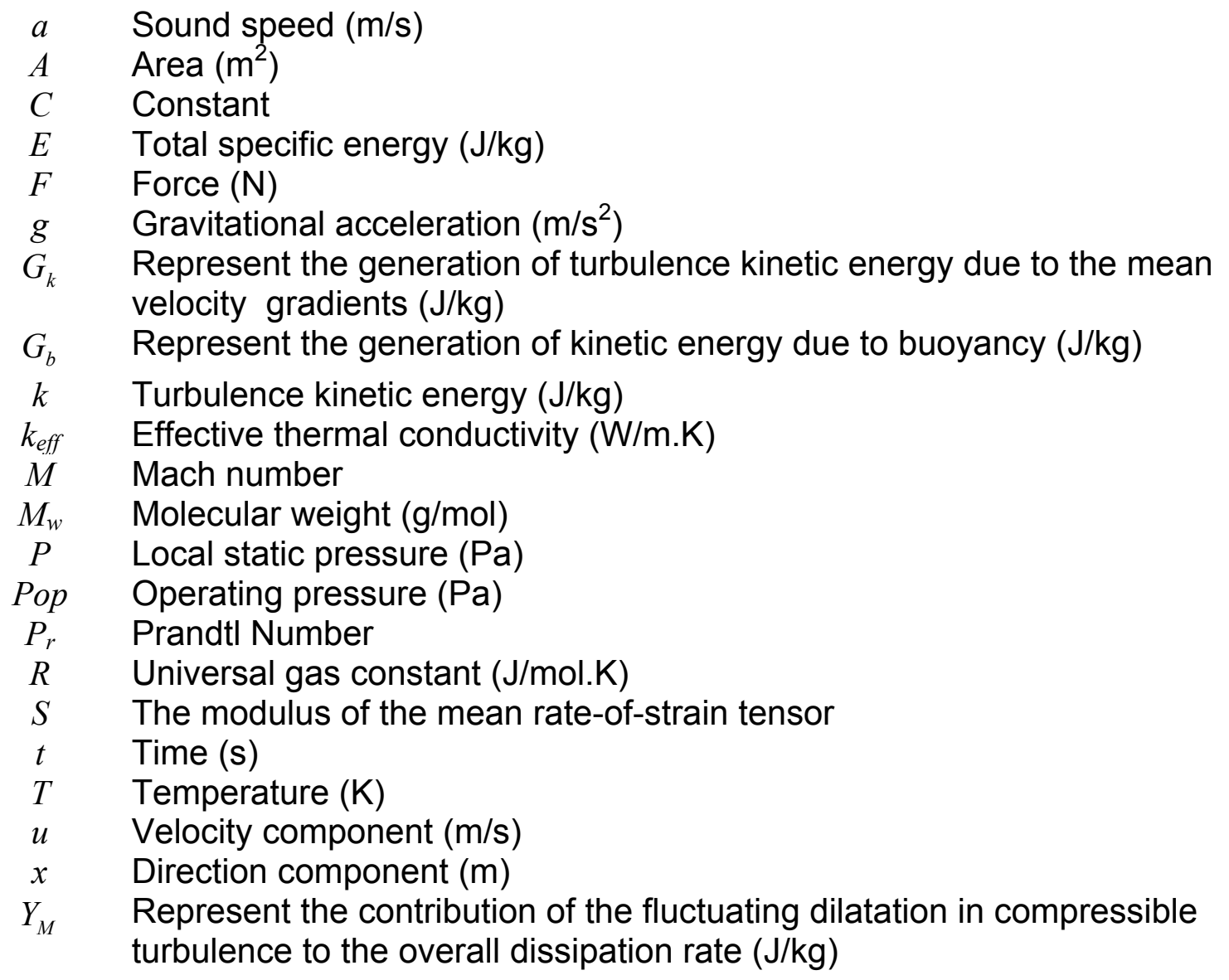

\section{Greek Symbols}

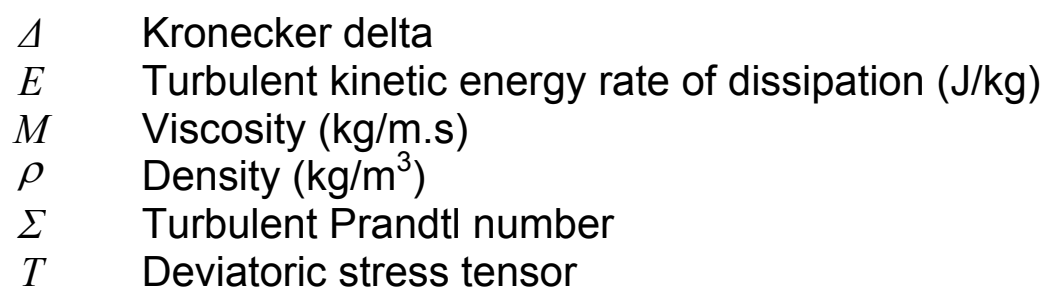

\section{Subscript}
Eff Effective
I Free index
$J \quad$ Free index
$L \quad$ Free index
$T$ Turbulent
$E \quad$ Relative to Turbulent kinetic energy rate of dissipation
$K \quad$ Relative to Turbulent kinetic energy 


\section{INTRODUCTION}

Many industries including automotive, printing, and aerospace use pneumatic systems for both manufacture and operation. Pneumatic control valves are an essential element of any pneumatic system and regulate the fluid flow or pressure of the system; this duty may involve stopping and starting flow, controlling the flow rate, diverting flow, preventing back flow, controlling pressure, or relieving pressure. The flow problems arising in pneumatic applications have a very complex structure. The gas flow through valves, nozzles etc. is characterized by viscous effects, turbulence, vortices, flow separation, and shock waves. These may affect adversely on the system resulting in noise and vibration. Since most pneumatic components have very small geometrical dimensions, it is often not possible to perform detailed flow measurement of the internal flow structure. Hence the importance of computational fluid dynamics flow simulations becomes evident which allow detailed quantification and visualisation of the flow in order to study the impact of geometry variations. In this paper a conventional spring loaded safety relief valve has been investigated using computational fluid dynamics. These valves are designed to protect a pressure system against excessive operating pressure. They are required to open at a predetermined system pressure and to discharge an amount of fluid to ensure a pressure reduction and then to close after the normal system pressure has been restored. Hence when studying safety relief valve performance it is very important to understand the mass flow rate through the valve with respect to the moving elements and the forces exerted on the element during opening and closure [1]. While the operation of the valve is essentially a dynamic process the operation of the valve can be understood by assuming quasi static conditions whereby the aerodynamic force and mass flow acting on the moving valve element are functions of the valve position alone. This assumes pressure wave effects are negligible which is more applicable to the closing than the opening phase of a safety relief valve operation. However, the initial design process is often based on the quasi steady approach and directly uses the force-lift and mass flow-lift characteristics of the valve. In this paper, these characteristics are determined experimentally and predicted using CFD techniques. It will be shown that the trends evident in the characteristics can be explained using the detailed flows predicted from the CFD calculations. The accuracy of the predictions will be discussed and the limitations of the modelling approach discussed.

\section{LITERATURE REVIEW}

Safety relief valves have various types and methods of operation such as the direct operated spring loaded, diaphragm, pilot operated...etc. Safety relief valves are used in many applications from the food processing, chemicals industries, pneumatics ...etc. so they have been studied and investigated in many different ways and for different reasons. Classification of safety valves with basic construction and operation was presented by Gringberg and Krichker [2]. Sharma [3] discussed in detail safety relief valves in accordance with the ASME Code in conjunction with design methods for the valve components including nozzle, seats, spindle and springs. These publications give the general background knowledge on various aspects of valves, however they fail to provide any insight to the compressible flow conditions that occur within the valve. This is not surprising given the complex flows that exist in the valve and until recently the 
lack of available, experimental and theoretical tools to assess the flows. Thus industry has relied on trial and error methods and experience gained from experimental testing. Attempts have been made to model valve operating conditions using one dimensional model by simplifying the valve geometry. For example, Parker [4] developed a one dimensional flow analysis through a general safety valve considering the pressure - lift characteristics and showed reasonable accuracy when compared with experimental test data. Similarly, a one dimensional model was developed by Francis [5] who divided the flow regions around the disc into different zones to calculate the pressure in each one and hence get the force-lift characteristics. The predicted results were compared with published experimental data. These publications were a good start in studying the compressible flow through safety relief valves and emphasised the importance of the mass flow and force variation with lift as dominant characteristics in valve performance.

With the development of computational fluid dynamic techniques (CFD) and increased computing power the ability to analyse the complex multi-dimensional compressible flow became possible. For example, Merati et al [ 6 ] by using FLUENT and a two dimensional model, the flow around a V-sector ball valve used in a pulp and paper mill has been investigated to enhance valve operation and decrease vibrations. Pressure, mass flow rate and pressure fluctuations were all measured experimentally and the flow was visualised by a high speed camera through a transparent housing of the valve. However, no explicit comparison between the predicted and the experimental results was applied. Other attempts have been carried out to understand the compressible flow behaviour through pneumatic components, Berger [7] simulated the flow in 2 pneumatic components with very simple geometrical shape. The commercial CFD code TASCflow was used to solve the mass averaged Navier- Stokes equations with the $k-\varepsilon$ model in a two dimensional axisymmetric model. The predicted results showed good agreement with the experimental results encouraging the use of CFD techniques to predict flow in pneumatic components. Surprisingly there are few published studies of using computational fluid dynamics methods to design or improve safety relief valves. A CFD model of fluid flow through a pressure relief valve was developed by Sethi and Sabet [8] using the PHOENICS code. Air as an ideal gas fluid was used as the flowing fluid through the relief valve. Steady state Euler equations were used. Predicted results of the disk force and mass flow rate versus lift showed good acceptance; but including the viscosity and transient terms of Navier stokes equations will make the solution more general and realistic. Bilanin and Teske [9] applied the full Navier Stokes equations to flow through a spring loaded safety relief valve to examine and improve the safety valve performance. The predicted results were compared with another calibrated model "COUPLE". No experimental work was carried out to validate the predicted results. Kim et al [10] studied an LNG safety valve performance using CFD techniques to improve its performance and develop a design tool. A two-dimensional, axisymmetric, model using the compressible Navier-Stokes equations is carried out to simulate the gas flow only between the nozzle exit and valve sheet, the predicted results obtained at different lift to radius ratio $(\mathrm{L} / \mathrm{R})$ and operating pressures $(\mathrm{PO} / \mathrm{Pa})$. Predicted CFD results were compared with a one dimensional analytical calculation and gave reasonable agreement. No experimental work was carried out. In a similar manner, Dempster et al [11] developed a two dimensional axisymmetric model of a safety relief valve to predict the flow and force characteristics to develop a design methodology for the safety valves using CFD techniques. The model used Reynolds Average Navier Stokes equations in conjunction with the Energy Equation and the standard k- $\varepsilon$ model to account for turbulence effects. The FLUENT software was used for the solution considering air as an ideal gas. A comparison of predictions with the experimental results gives excellent 
agreement but showed a significant sensitivity to geometry. These studies are encouraging and suggest that progress is being made in the analysis of relief valves, with CFD being the main tool of choice in understanding the operation of pneumatic components in general.

\section{MODELING AND COMPUTATIONAL WORK}

The safety relief valve considered in this study has a 1/4" orifice size and well used in the refrigeration industry; however it is used here in a pneumatic application. Figure 1 shows a cross sectional drawing of the entire valve. The safety relief valve is set to open at a pressure safely below the bursting pressure of a pressurised system. The piston (2) is held against the seat by a loaded spring (7) which is fitted between the gland insert (5) and the spring guide (6); excessive pressure forces the disk to open. The valve is designed such that when the valve opens slightly, the opening force builds up to open it fully and to hold the valve open until the pressure drops a predetermined amount. The relieving pressure is set by the initial compression of the spring which can be altered through the adjusting gland (4). Minor modifications have been applied to the valve to facilitate the experimental work; a $4 \mathrm{~mm}$ diameter rod has been fitted to the piston rear, the Adjusting gland (4) and the Adjusting gland insert (5) have been combined and replaced by a single equivalent component and the spring (7) has been cut to a smaller length. It is believed that these modifications have no significant effect on the measured or the predicted values of the mass flow rate, back pressure or the fluid forces on the piston. To verify this assumption, experimental work has been carried out on the entire assembled valve and the modified valve and will be described later.

To allow computational efficiencies a two dimensional axisymmetric model has been developed to represent the safety valve geometry, Fig. 2. In this model the flow areas between the piston and the body and the gland exit holes, also shown on Fig. 1 have been represented as equivalent annulus areas. The CFD code FLUENT has been used with the Reynolds Averaged Navier-Stokes (RANS) combined with the energy equation and the $\mathrm{k}-\varepsilon$ turbulent model to predict the highly compressible flow through the valve. Model governing equations are presented in Appendix I. Air as an ideal gas has been adopted to be the fluid. The computational mesh has a total of 6400 quadrilateral cells distributed giving a mesh density of $7 \mathrm{cells} / \mathrm{mm}^{2}$ and a 20 min typical solution time on a 2.4 Ghz desktop PC. Pressure boundary conditions have been used at the inlet and outlet and are restricted to a maximum laboratory pressure of 15.9 barg (230 psig). For this study, pressures in the range 10-13.8 barg (145-200 psig) have been chosen to allow the valve flowrates to be matched with the laboratory compressor flow capability.

Back pressure plays an important role in influencing the valve performance; that is back pressure develops an opposing force on the piston rear side which decreases the net force exerted by the fluid on the piston. For the relief valve under study, the adjusting gland area and its resistance to flow determines a back pressure hence will decrease the total force on the piston at any lift. However, it is only at higher piston lifts where the flow is significant that a notable back pressure develops. To evaluate this significance, two computational models of the valve have been developed: in the first, the entire valve has been modeled with the gland area presented as an equivalent annulus area, and in the second, the gland has been removed. 


\section{MODEL VALIDATION}

To validate the predicted results, several experiments have been applied to the safety relief valve. A layout and a schematic drawing of the test rig is shown in Fig. 4 and Fig. 5 it has been constructed to measure the net force acting on the piston, pressure and the mass flow through the valve at any piston lift. The test rig consists of connecting the valve to the end of a $150 \mathrm{~mm}$ diameter pipe supplied by compressed air. The valve piston is connected via a rod to a force transducer and a linear cross slide is used to facilitate movement of the piston and the determination of a force-lift characteristic. The mass flow is measured by a Sierra Instruments vortex mass flow meter, located in an upstream compressed air supply line. The force-lift and mass flow rate-lift characterestics are steady state characteristics and to achieve this the upstream pressure has been maintained constant at any lift value by controlling an upstream throttle valve located in the main air supply line. The valve supply pressure is measured using a bourdon gauge positioned upstream of the valve in the $150 \mathrm{~mm}$ diameter pipeline and the piston back pressure is measured by a bourdon gauge connected to a pressure tapping on the valve body. The piston position (piston lift) is measured using a digital 'dial' guage which has an accuracy of $0.001 \mathrm{~mm}$, and results in an relative error of the order of $0.01 \%$ to $0.6 \%$. For the force measurments the accuracy is 1 Newton which gives a measurement error range of $0.5 \%$ to $2 \%$. The accuracy of the pressure measurement is $3 \mathrm{kPa}$ which gives a relative measurement error of $0.2-2.5 \%$. The mass flow rate is accurate to $1 \%$ of the reading.

The first group of experimental tests were used to validate the predicted results and to verify that removing the spring of the safety relief valve will not affect the mass flow rate, piston back pressure or the piston force. These experiments were caried out at various pressure ranges between $10-14$ barg (145 and 200 psig). Fig. 3 shows the comparison of the experimental results obtained when testing the complete valve and the modified valve at 11.7 barg (170 psig) inlet pressure, and shows close correspondence for both conditions. It was concluded that the spring had no effect on either the force or mass flowrate and need not be modeled in the CFD simulation. All subsequent tests were carried out with the spring removed. The second group of experimental tests were carried out on the valve with and without the adjustment gland/insert combination. This allowed back pressure effects to be removed and geometry modelling of the gland to be addressed separately. The applied inlet pressure was in the same range 10-14 barg (145:200 psig).

\section{RESULTS AND DISCUSSION}

Contours of static pressure, static temperature, velocity and Mach number have been obtained for the flow through the valve at different piston positions. Figures $6,7,8$ and 9 show the pressure, temperature, velocity and Mach number contours at an inlet pressure value of 11.7 barg (170 psig) and a lift of $2.5 \mathrm{~mm}$, which is in the fully open operating range of lifts. The figures show the significant variations of flow properties encountered in the valve. From Mach numbers of 0 to 1.6, temperature variations - 60 ${ }^{\circ} \mathrm{C}$ to $20^{\circ} \mathrm{C}$ and velcocites from $0-400 \mathrm{~m} / \mathrm{s}$. The variation with lift of the mass flow rate and net piston force obtained with and without the gland are shown on Fig.10 and Fig.11a along with CFD predictions (with gland). Figure 10 indicates that the CFD model provides an accurate prediction of the flowrates at all lifts. The experimental 
results of the mass flow rate through the valve with and without the gland proves that the gland has no significant effect on the mass flow rate. This suggest that the simplified model of the valve without the gland or other complex exit geometry, could give accurate predictions for the mass flow rate-lift characteristics. However, in Fig.11a and $11 \mathrm{~b}$ the force-lift curves indicate that the gland has a noteable effect on the piston net force. The results with the gland removed show higher net forces than with the gland in place and is caused by the absence of a back pressure. The predicted forces compare well with the measurements. However, when the gland is in place the predictions for both force and back pressure are less accurate and are due to the limitations of modelling the three dimensional flow through the gland holes using a twodimensional model, as is done here. Additional errors arise from the difficulty in accurately representing the geometrical edges of the gland holes correctly as previously discussed by Dempster et al [16 ].

\section{Flow and Force-Lift Characteristics}

The specific form of the flow and force characteristics can be understood by examining the detailed predicted results for a range of lifts. Fig.10 shows the mass flowrate for a range of lifts and on this curve regions I and II are identified. In region I, which occurs for lifts between 0 and $1.2 \mathrm{~mm}$, a rapid increase in mass flow rate occurs for a slight change in piston lift. Thereafter, the mass flow changes more slowly to a near constant value. The reason for these changes can be explained by examination of the Mach number and pressure distributions local to the piston in the valve. Figs. 12, 13 and 14 show these parameters for a wide range of lifts. Fig.12 shows the Mach number contours in the flow between the valve seat and piston face for lifts for region I, ie 0.3 to $1.2 \mathrm{~mm}$. The figure indicates that for these lifts the flow is choked in a plane between the seat and the piston; the dashed lines in Fig. 12 showing the choking plane for each lift. The mass flow rate is critical and controlled by the local geometry. Since the inlet stagnation pressure and stagnation temperature is fixed for each of the lift positions the mass flowrate is dependent only on area and this a near linear function with lift resulting in the linear change of mass flowrate seen in Fig.10 for Region I. When the lift is greater than $1.2 \mathrm{~mm}$ the choking plane moves to a position at the exit from the annular passageway between the piston and the valve body, as shown on Fig.13 and remains at this position for any further increase in lift. The slower increase in mass flow for higher lifts that can be seen in region II of Fig.10 is due to the increase in pressure at the inlet of the annular passageway. This is indicated in Fig.14 which shows an increase in pressure downstream of the valve seat as the piston lift increases. This will continue to increase as the piston moves away from the seat and will eventually approach the limiting upstream stagnation pressure of 11.7 barg. This also limits any increase in mass flowrate and explains the near constant mass flow found at higher lifts in Fig.10.

In a similar manner an understanding of the force-lift characteristics can be obtained by examining the detailed CFD predictions. Fig.11.a shows three main regions, region I between 0 and $0.4 \mathrm{~mm}$ lift when the net force linearly increases. Region II, which occurs between 0.5 and $1.5 \mathrm{~mm}$ and shows an increasing net force, but at a significantly reduced rate compared to Region I. A final region, region III can be identified for all lifts above $1.5 \mathrm{~mm}$ and shows a steady increase of the net force but finally settles to a steady value. Fig. 14 shows the pressure distribution at the piston front and rear face for a range of lifts. In Region I and at zero lift the net force is dictated by the upstream stagnation pressure acting between the seat sealing locations. As the 
piston lifts, a choking plane is established that ensures that the stagnation pressure acts across the majority of the piston inner face. However at lifts between 0 and $0.4 \mathrm{~mm}$ an increase in force is achieved by the expanding gas close to the valve seat. The net force in Region I is influenced primarily by increases in pressure over the inner piston area, (Area 1 in Fig. 14) and no significant back pressure. However, as the piston lifts further into Region II the flow rate increases significantly causing an increase in back pressure as shown in Fig. 11.b and an increase in pressure across the outer periphery of the piston front face, (Area 2 in Fig 14). The increase in piston back pressure prevents the force from increasing at the same rate as in Region I. As the lift progresses into Region III the flow rate begins to stabilise because the choking position is now fixed (see above) and since the back pressure is flowrate dependent it also reaches a steady value. At the higher lifts of Region III both the pressure at inner and outer regions of the piston front face will increase towards the upstream stagnation pressure, (In Fig.14 the pressure at face A2 was 6.5 barg for a $1.2 \mathrm{~mm}$ lift ) then 8.5 barg for a $4 \mathrm{~mm}$ lift. Since this is a fixed pressure for all lifts then this combined with a steady back pressure will eventually produce a steady net force. Thus the trends found for both mass flow and force-lift characteristics can be explained in detail by using the CFD predictions.

\section{CONCLUSION}

A detailed understanding of the compressible flow through a safety relief valve has been presented. A two dimensional axisymmetric computational model based on a RANS and $k-\varepsilon$ turbulence model has been found satisfactory in predicting the flow and forces acting on internal valve elements. The model has been shown to provide an excellent comparison with experimental measurement of mass flow and force for a range of piston lifts. Importantly the CFD predictions allowed a detailed understanding between valve geometry and the trends observed in the valve flow and force characteristics. Since these characteristics are fundamental for valve operation an understanding of the interaction between the flow and valve geometry and the effects on the characteristics is necessary for the development of more effective designs. It is also important to add that for this study simplification of the valve model can be achieved by neglecting the valve spring and the valve gland if only mass flow prediction is desired and will lead to a significant reduction in computational effort. However, for prediction of the piston forces a three dimensional model of the gland geometry may be required to ensure accurate prediction of the piston back pressure.

\section{REFERENCES}

[1] Smith P. and Zappe R.W. , Valve Selection Handbook, $5^{\text {th }}$ edition, Elsevier 2004

[2] Grinberg S. and I. R. Krichker. Classification of safety valves. Translated from Khimicheskoe I Neftyanoe Mashinostriroenie, No. 10 pp. 12

[3] Sharma D. K. State-of-the-art design of spring loaded safety valves. Joint conference of the Pressure Vessels and Piping, Materials, Nuclear Engineering and Solar Division, 1981

[4] Parker G. J. Pop Safety valves: a compressible flow analysis. International Journal of Heat and Flow. Vol. 6, No 4, 1985

[5] Francis J., Zone Modeling of High Lift Safety Relief Valves Subject To Choked 
Compressible Flow., Proceeding Of The $3^{\text {rd }}$ International Seminar on Fire and Explosion Hazards, pp.795-806,2001

[6] Merati P., Macelt M. J. and Erickson R. B., Flow Investigation around a V-sector ball valve, Journal of Fluid Engineering, Transactions of the ASME, Vol. 123, 2001

[7] Berger H., Numerical Simulation of Gas Flow in Pneumatic Components, Forschung im Ingenieurwesen - Engineering Research Vol. 58 No. 3, 1992

[8] Sethi S. and Sabit A., Predicting the Fluid Flow Through a pressure Relief Valve using the CFD Code PHONICS, Proceeding of the 11th Annual Simulators Conference, Vol. 26, Part 88, pp. 229-235, 1994

[9] Bilian A.J. and Teske M.E., Modeling Flow Through spring loaded Safety Valves, ASME conference, Vol. 190, pp.29-36, 1990

[10] Kim H. D. , Lee J. H. and Park K. A., A Study of the Gas Flow through a LNG Safety Valve, Journal of Thermal Science Vol.15, No.4, 2006

[11] Dempster W., Lee C. K. and Deans J., Prediction of the Flow and Force characteristics of a Safety Relief Valves, Proceeding of ASME PVP Conference, 2006

[12] FLUENT V6.3 reference manual, www.fluent.co.uk, 2007

[13] Joun D. Anderson, Computational Fluid Dynamics with applications, McGraw Hill USA, 1995.

\section{Figures}
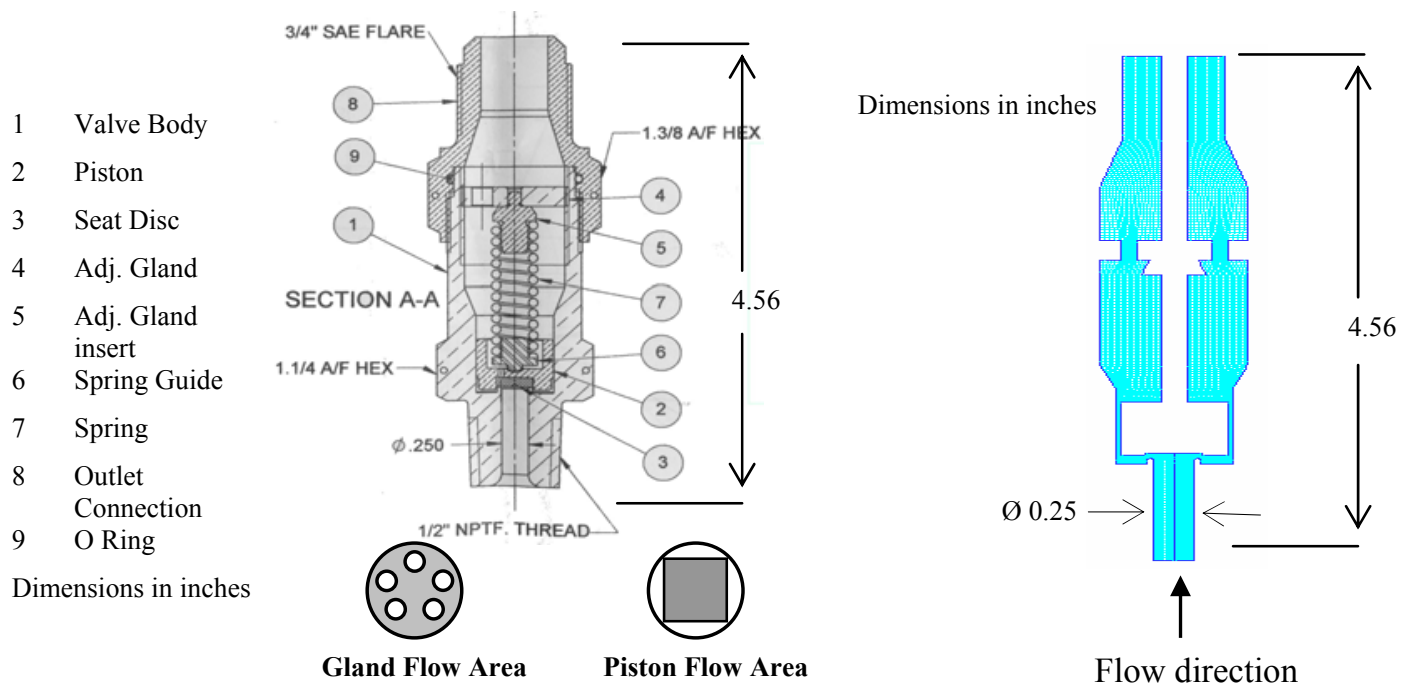

Fig.1. Valve Assembly
Fig. 2. Computational model of the valve at lift $1 \mathrm{~mm}$ 


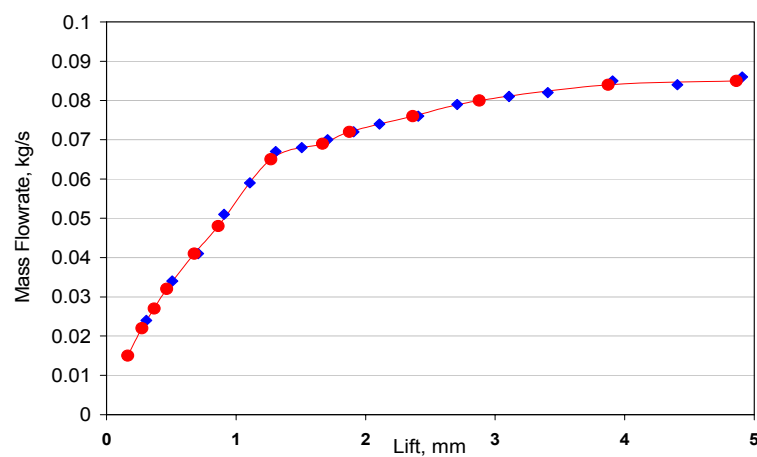

- Mass Flowrate (Complete Valve) - Mass Flowrate (Spring Removed)

(a)

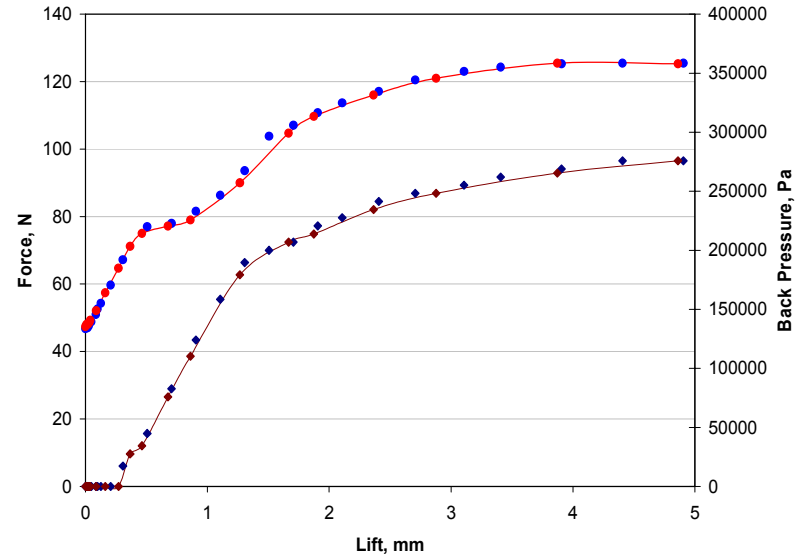

- Complete Valve (Spring + Gland Included) $\rightarrow$ - Spring Removed

- Back Pressure (Complete Valve) $\rightarrow$-Back Pressure (Spring Removed)

(b)

Fig.3. Comparison between mass flow rate, force, back pressure with and without the spring at inlet pressure170 psi.

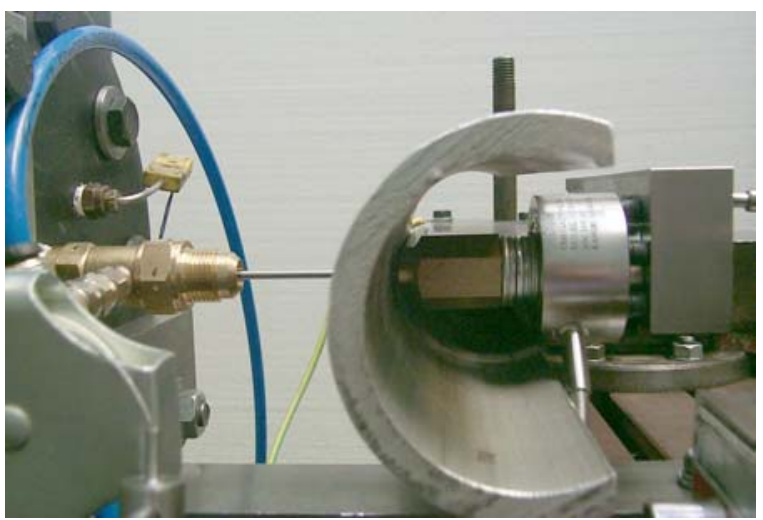

Fig.4. Test rig Layout
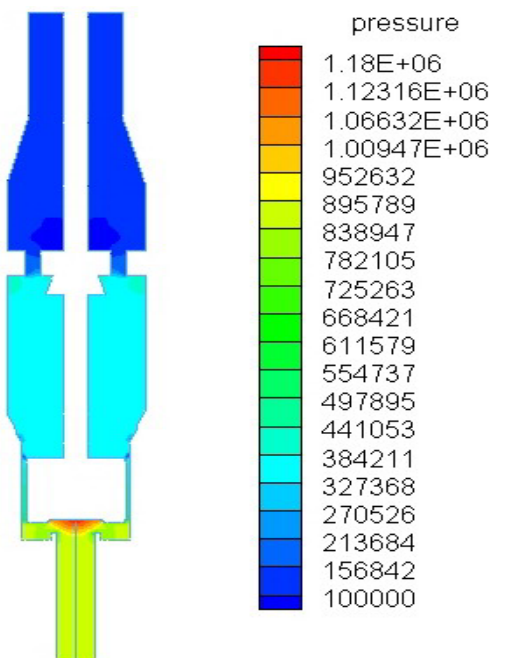

Fig.6. Static pressure contours (Pag) (inlet pressure 11.7 barg, lift $2.5 \mathrm{~mm}$ )

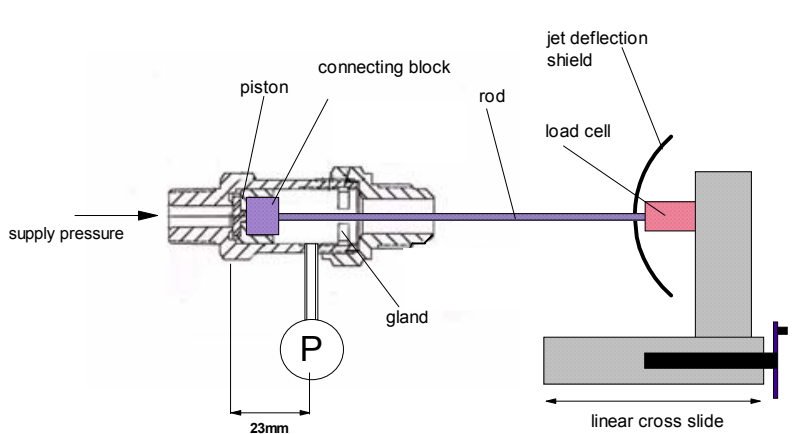

Fig.5. Schematic drawing of the test rig

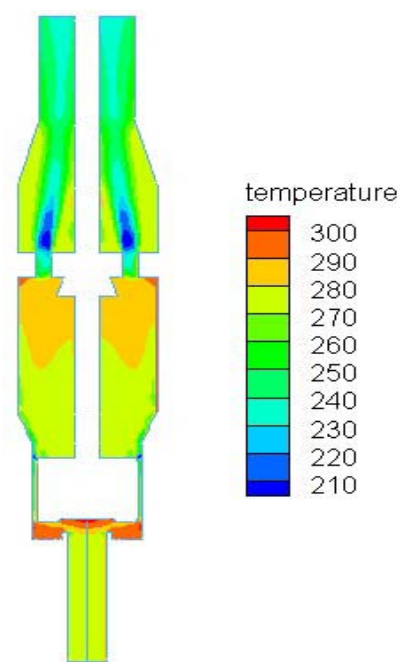

Fig.7. Static temperature contours $(\mathrm{K})$ (inlet pressure 11.7 barg, lift $2.5 \mathrm{~mm}$ ) 


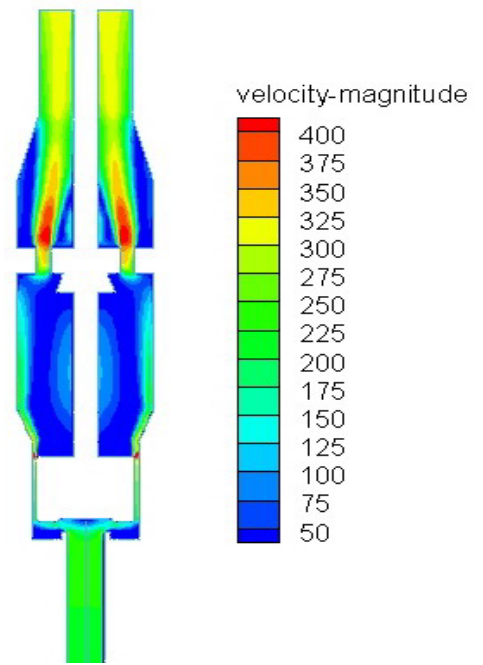

Fig.8. Velocity magnitude contours $(\mathrm{m} / \mathrm{s})$ (inlet pressure 11.7 barg, lift $2.5 \mathrm{~mm}$ )

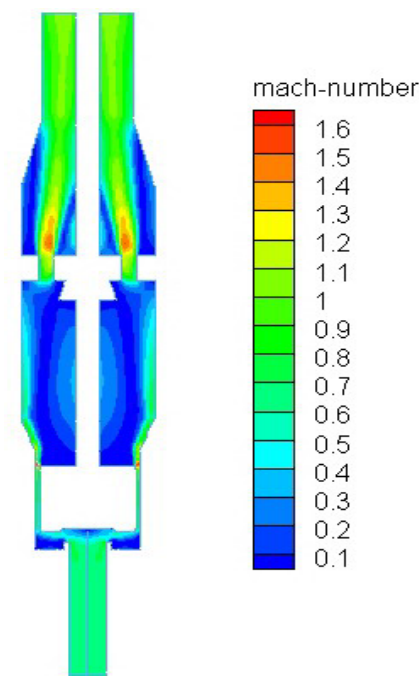

Fig. 9. Mach number contours ( inlet pressure 11.7 barg , lift $2.5 \mathrm{~mm}$ )

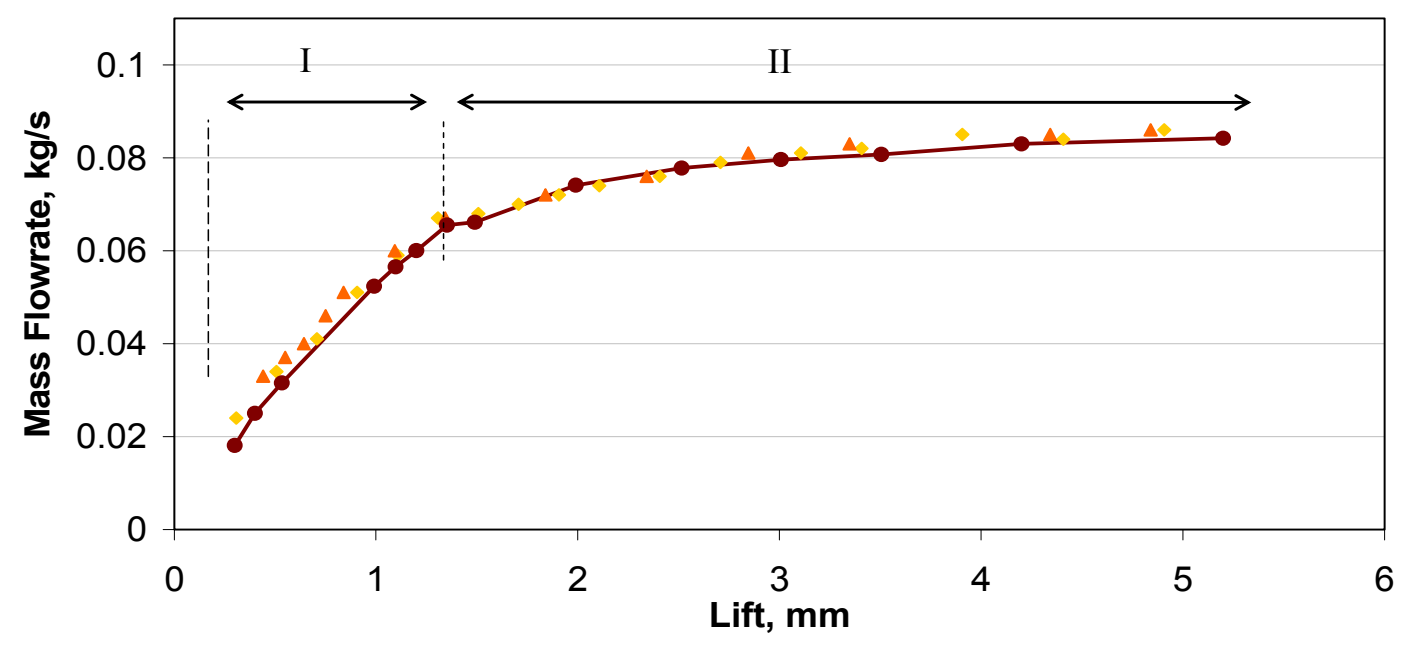

Exp.with gland $\Delta$ Exp. without gland $\rightarrow$ Predicted round edges

Fig.10. Mass flow-lift characteristics with and without the gland experimental and CFD predicted results at $P_{i}=11.7$ barg. 


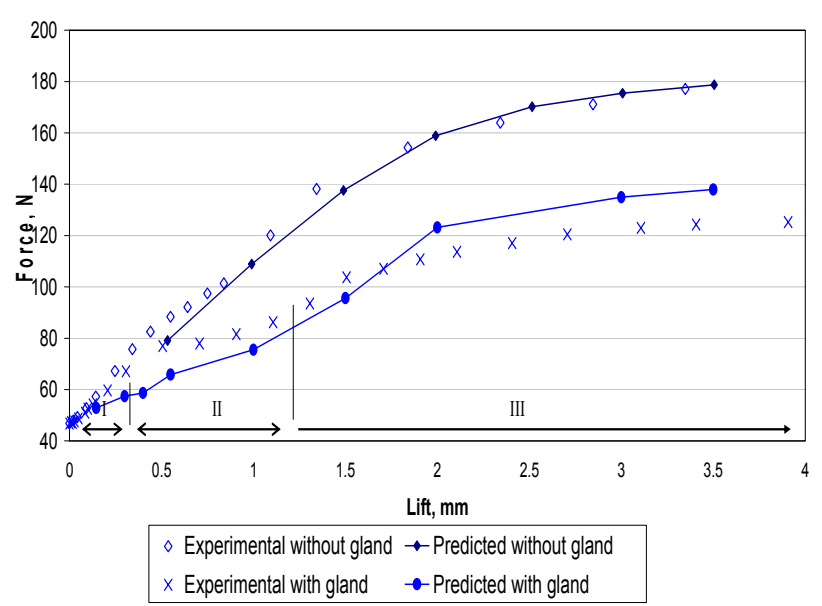

(a)

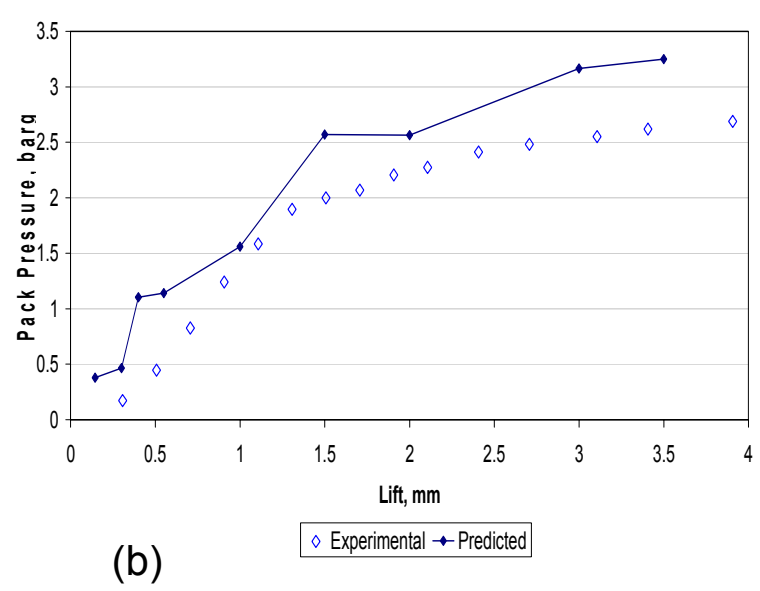

Fig.11. (a) Force-lift characteristics with and without the gland and (b) piston back pressure - lift experimental and CFD predicted results at $\mathrm{P}_{\mathrm{i}}=11.7$ barg.

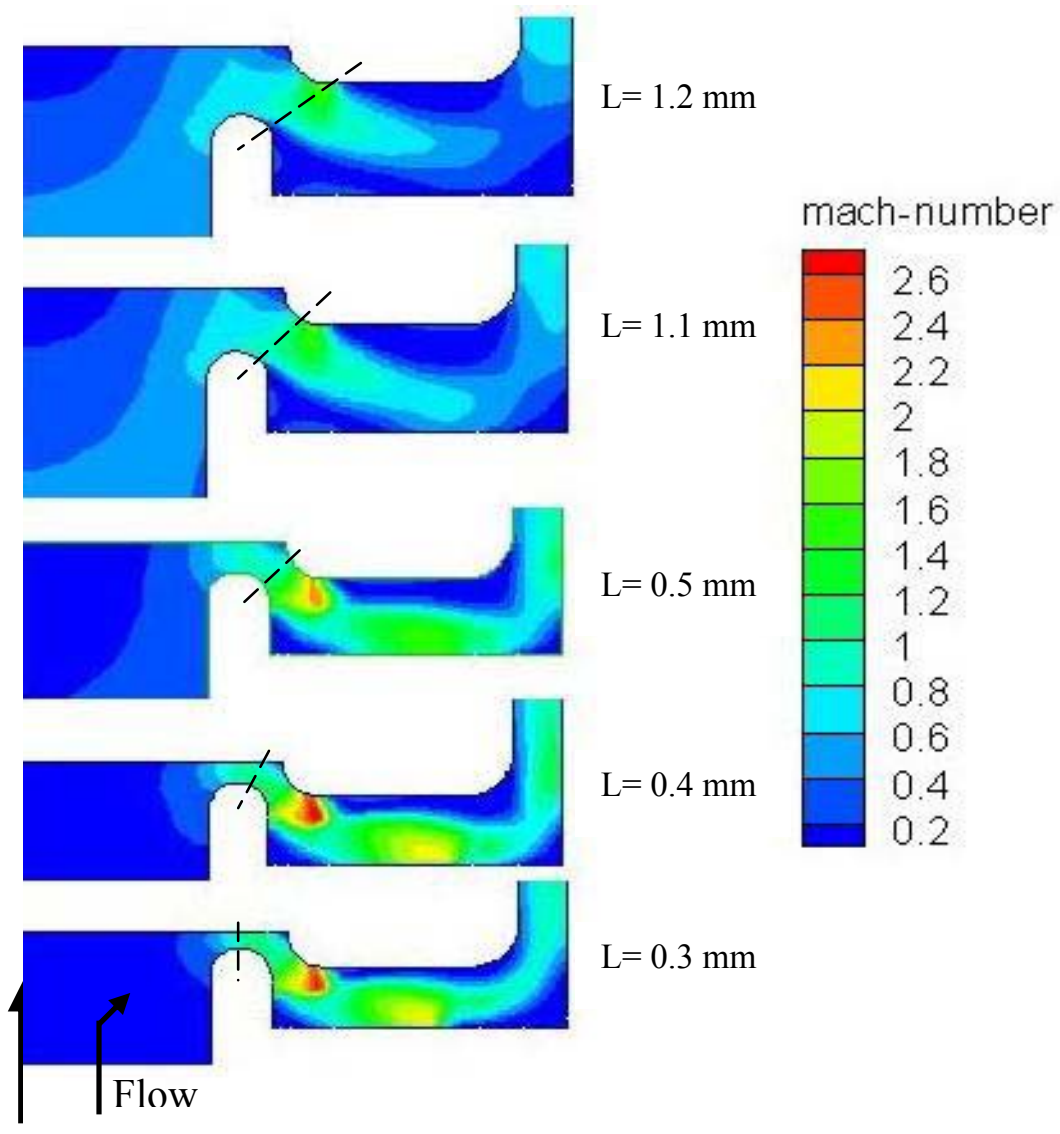

Fig.12. Mach number contours between valve seat ad piston at Inlet pressure $=11.7$ barg and different lift values ( choking planes shown by dashed line) 


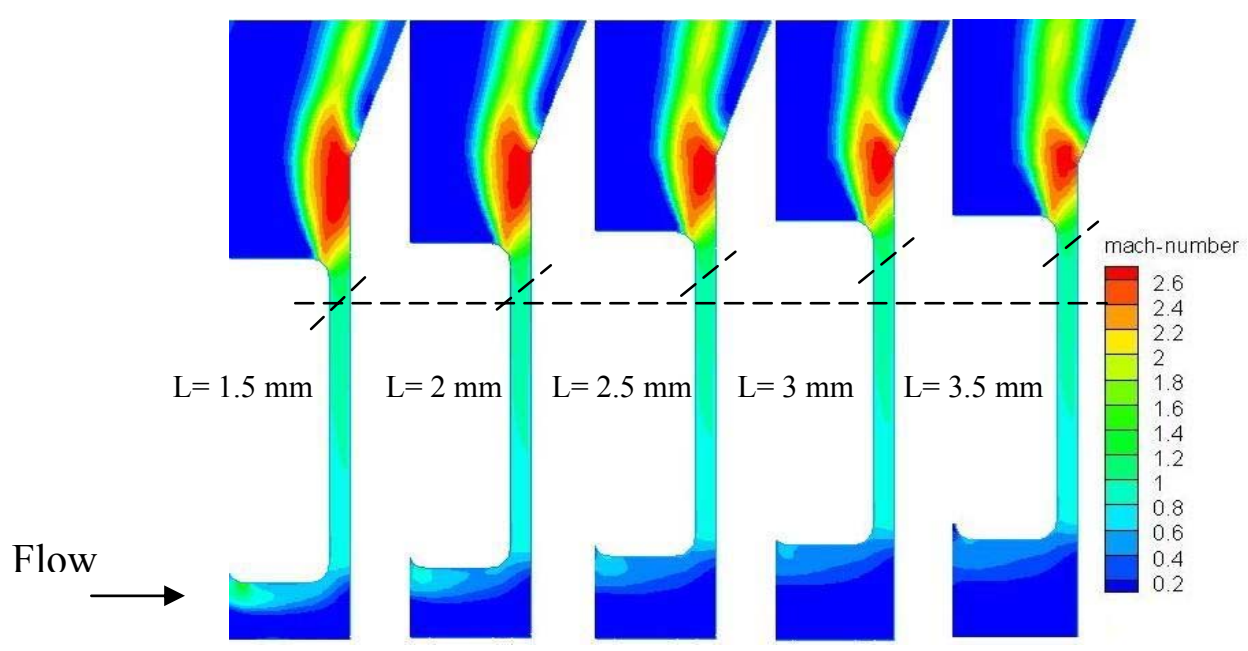

Fig.13. Mach number contours at Inlet pressure $=11.7$ barg at different lift values ( choking planes, shown by dashed line moves with piston position)

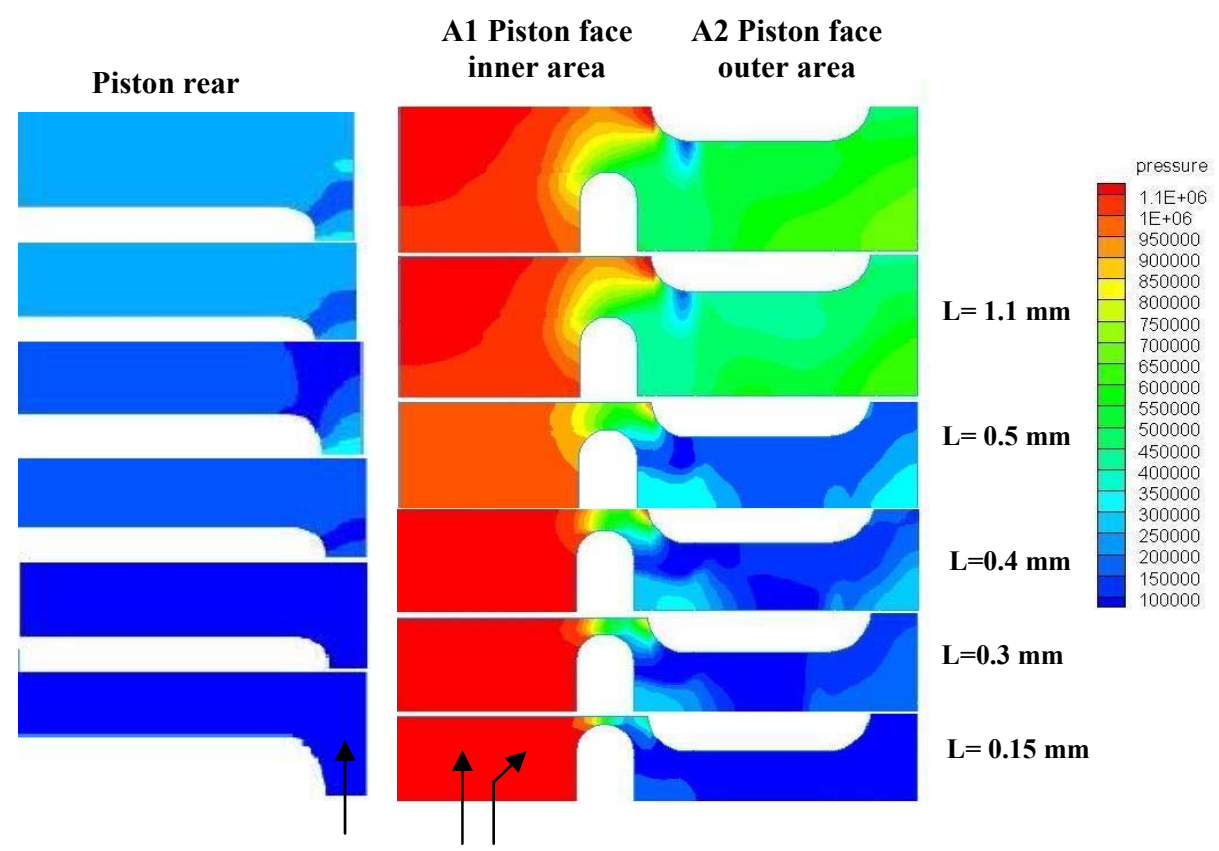

Flow direction

Fig.14. Static pressure contours at Inlet pressure $=11.7$ barg pressure on piston face and back pressure behind piston. 


\section{Appendix I}

Reynolds Averaged Navier-Stokes equations (RANS) in Cartesian tensor form $\frac{\partial \rho}{\partial t}+\frac{\partial}{\partial x_{i}}\left(\rho u_{i}\right)=0$

$\frac{\partial}{\partial t}\left(\rho u_{i}\right)+\frac{\partial}{\partial x_{j}}\left(\rho u_{i} u_{j}\right)=-\frac{\partial p}{\partial x_{i}}+\frac{\partial}{\partial x_{i}}+\left[\mu\left(\frac{\partial u_{i}}{\partial x_{j}}+\frac{\partial u_{j}}{\partial x_{i}}-\frac{2}{3} \delta_{i j} \frac{\partial u_{l}}{\partial x_{l}}\right)\right]+\frac{\partial}{\partial x_{j}}\left(-\rho \overline{u_{i}^{\prime} u_{j}^{\prime}}\right)$

Where the Reynolds Stresses $\frac{\partial}{\partial x_{j}}\left(-\rho \overline{u_{i}^{\prime} u_{j}^{\prime}}\right)$ is obtained from the equation

$\frac{\partial}{\partial x_{j}}\left(-\rho \overline{u_{i}^{\prime} u_{j}^{\prime}}\right)=\mu_{t}\left(\frac{\partial u_{i}}{\partial x_{j}}+\frac{\partial u_{j}}{\partial x i}\right)-\frac{2}{3}\left(\rho k+\mu_{t} \frac{\partial u_{k}}{\partial x_{k}}\right) \delta_{i j}$

and $\mu_{t}=\rho C_{\mu} \frac{k^{2}}{\varepsilon}$

The standard k- $\varepsilon$ turbulence model

$\frac{\partial}{\partial t}(\rho k)+\frac{\partial}{\partial x_{i}}\left(\rho k u_{i}\right)=\frac{\partial}{\partial x_{j}}\left[\left(\mu+\frac{\mu_{t}}{\sigma_{k}}\right) \frac{\partial k}{\partial x_{j}}\right]+G_{k}+G_{b}-\rho \varepsilon-Y_{M}$
$\frac{\partial}{\partial t}(\rho \varepsilon)+\frac{\partial}{\partial x_{i}}\left(\rho \varepsilon u_{i}\right)=\frac{\partial}{\partial x_{j}}\left[\left(\mu+\frac{\mu_{t}}{\sigma_{\varepsilon}}\right) \frac{\partial \varepsilon}{\partial x_{j}}\right]+C_{1 \varepsilon} \frac{\varepsilon}{k}\left(G_{k}+C_{3 \varepsilon} G_{b}\right)-C_{2 \varepsilon} \rho \frac{\varepsilon^{2}}{k}$

Where

$$
\begin{aligned}
& G_{k}=\mu_{t} S^{2} \text { and } S=\sqrt{2 S_{i j} S_{i j}} \\
& G_{b}=-g_{i} \frac{\mu_{t}}{\rho P_{r_{t}}} \frac{\partial \rho}{\partial x_{i}} \\
& Y_{M}=2 \rho \varepsilon M_{t}^{2} \text { and } M_{t}=\sqrt{\frac{k}{a^{2}}}
\end{aligned}
$$

Energy Equation

$$
\frac{\partial}{\partial t}(\rho E)+\frac{\partial}{\partial x_{i}}\left[u_{i}(\rho E+p)\right]=\frac{\partial}{\partial x_{j}}\left(k_{e f f} \frac{\partial T}{\partial x_{j}}+u_{i}\left(\tau_{i j}\right)_{e f f}\right)
$$

Where

$$
\begin{aligned}
& \left(\tau_{i j}\right)_{e f f}=\mu_{e f f}\left(\frac{\partial u_{j}}{\partial x_{i}}+\frac{\partial u_{i}}{\partial x_{j}}\right)-\frac{2}{3} \mu_{e f f} \frac{\partial u_{k}}{\partial x_{k}} \delta_{i j} \\
& k_{e f f}=k+\frac{c_{p} \mu_{t}}{P_{r_{i}}}
\end{aligned}
$$

Ideal Gas law

$$
\rho=\frac{p_{o p}+p}{\left(R / M_{w}\right) T}
$$

